\title{
INVESTIGATION OF CONFINEMENT EFFECTS FOR DETERMINING MOMENT CURVATURE AND INTERACTION DIAGRAM OF REINFORCED CONCRETE COLUMN
}

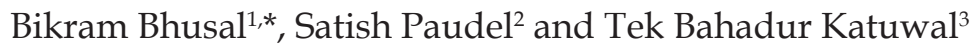 \\ ${ }^{1}$ Institute of Engineering, National College of Engineering, Tribhuvan University, Nepal \\ ${ }^{2}$ School of Civil Engineering and Technology, Sirindhorn International Institute of Technology, Thammasat \\ University, Pathum Thani, 12120, Thailand \\ ${ }^{3}$ Institute of Engineering, Pashchimanchal Campus, Tribhuvan University, Nepal \\ *E-mail: bikrambhusal103@gmail.com
}

\begin{abstract}
This paper presents the relevance of using various material models to represent the inherent material non-linearity of the cross-section in generating moment curvature relationship. Further, confinement effects are imposed on geometry and P-M diagram is constructed of typical crosssection of column adopted in Nepal. Also, the modelling capability and user defined modelling aspects in terms of section, material behavior is assessed and suitability of modelling criteria to depict the actual displacement capacity is studied. It was observed the ultimate curvature of the un-confined concrete section considered was obtained approximately to be 0.16 per $\mathrm{m}$ while for studied confined material models the curvature was obtained approximately to be $0.66 \mathrm{per} \mathrm{m}$. This increase in curvature is due to the confinement effect of the lateral ties. It was observed that the loss of strength of concrete in cover is compensated by use of the confinement since gain in axial and bending capacity of the confined concrete in comparison to unconfined one in compression control region. Hence, it is suggested to adopt the confined material model as user-defined for generating hinge property for non-linear analysis of the structures.
\end{abstract}

\section{Keywords}

Confinement, Material models, SAP 2000, hinges, Seismic Loading

\section{Introduction}

Columns are the primary structural members in structure designed to resist the imposed loading of any nature. Being major component for strength and ductility enhancement of the structure modelling of such members should be performed with due care. Since inelastic behavior is inherent in most of the structures so structural engineering has been adopting nonlinear static analysis procedures for analyzing such structures. Modelling non-linear is not a handy job so development of the several advance modelling tools for numerical analysis of structures have helped researchers to predict the complex non-linear behavior of the R.C structural system numerically. While adopting 
Nepal Engineers' Association, Gandaki these platforms users should be aware of the modelling capabilities of the tool without being completely dependent on the software. Since, numerical modelling for non-linear analysis includes the non-linear material behavior of the members as depicted by moment curvature relationship and interaction curves (Kwak and Kim, 2002), (Hede and Narayan, 2015) so an attempt is done to assess the modelling criteria for reinforced concrete column. A simple Methodology of construction of moment curvature relationship and interaction curves for the typical column section is proposed. A study of various confined material model to depict non-linearity of material in the form of post peak response and geometric nonlinearity in the form of hinges and inherent plastic behavior of the section is performed. Various documents including ATC-40 (Applied Technology Council, 1996)and FEMA 356 (Federal Emergency Management Agency, 2000) is widely adopted and researchers have been following the non-linear analysis provision as per these codes. Also, since analysis package SAP 2000 (SAP-2000, 2016) developed from Computer and Structures also adopt these guidelines so users usually adopt the default modelling approaches. Contrarily, the researcher might be fully dependent on the default modelling considerations of the tool and might be far off from the real response of the existing structure. So, a clear understanding of the numerical model its capability and procedure should be done to perform the nonlinear analysis (Zendaoui et al., 2016). This research paper focuses on the evaluation of behavior of a typical column cross-section for moment-curvature and interaction diagrams for various codal provisions using various material models.

\section{Geometry of Column Section}

To investigate the effect of material model in obtaining the effect of confinement on stressstrain curve a typical cross-section of column was considered. The adopted column consists of the column section usually used in residential building as depicted in Figure 1.
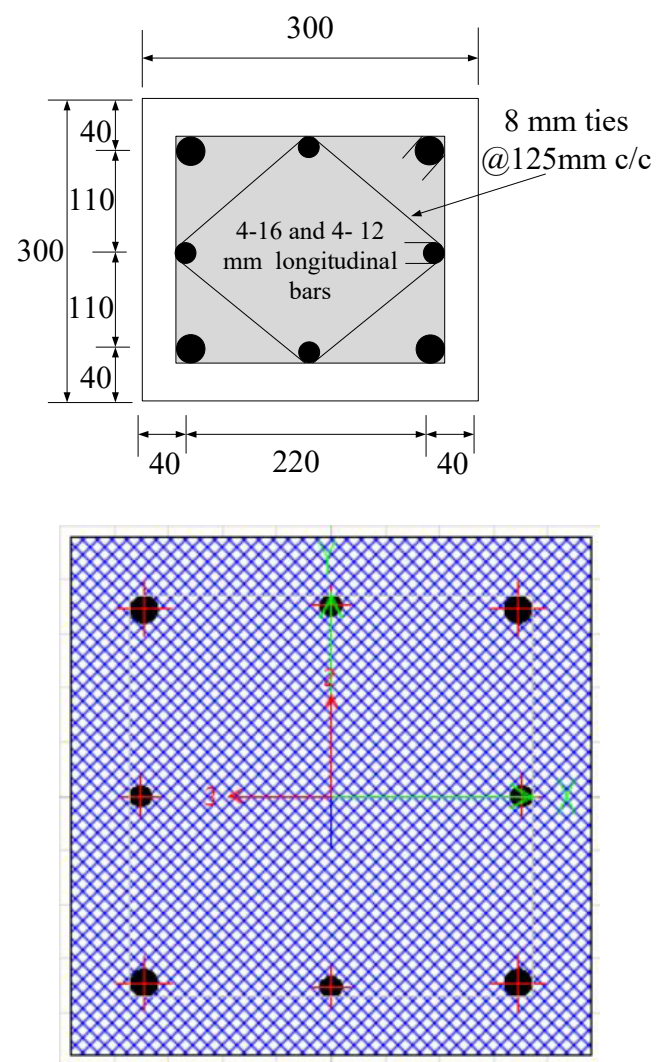

Figure 1: Cross-section of column

The column consists of size $300 \mathrm{~mm}$ (12 in.) by $300 \mathrm{~mm}$ (12 in.) with reinforcement details comprising of 4 corner bars of $16 \mathrm{~mm}$ and diagonal $12 \mathrm{~mm}\left(\rho_{l}=1.369 \%\right)$ and transverse $8 \mathrm{~mm}$ ties @125mm c/c $\left(\rho_{v}=0.268 \%\right)$. 


\section{Material Model}

Concrete is brittle material and behaves as unconfined concrete for low level of stress with no role of the transverse rebar and when the stress reaches the uniaxial strength the lateral ties acts so they are usually termed as passive confinement (Park, R., and Paulay, 1975). Confinement by lateral ties have less or no effect on the stress-strain curve until concrete reaches maximum stress level. As strain increases the stress-

strain curve of confined concrete depends on the volumetric ratio, strength of concrete and rebar, diameter and spacing of the stirrups etc. Since non-linear analysis of the structural frames includes the non-linear material behavior of the members and depicted by moment curvature relationship and interaction curves (Kwak and Kim, 2002), (Hede and Narayan, 2015). Several confined and unconfined concrete material models have been proposed for concrete including Mander et. al., 1988 (J. B. Mander, 1988) , Kent and Park, (1971) (Kent, D.C., and Park, 1971), Cusson-Paultre, 1995 (Cusson, D., and Paultre, 1995) and Hong-Hang Model (Suzuki et al., 2004).etc., and for steel (Indian Standard, 2000), (CP 110, 1972). In various codal provisions ((ACI Standard, 2014), (Thomas, 1990)) stress-strain curve of the concrete material has an initial parabolic ascending portion until strain of 0.002 followed by linearly descending portion which is sometimes even idealized as a straight line until the ultimate strain of 0.0035 (Indian Standard, 2000).

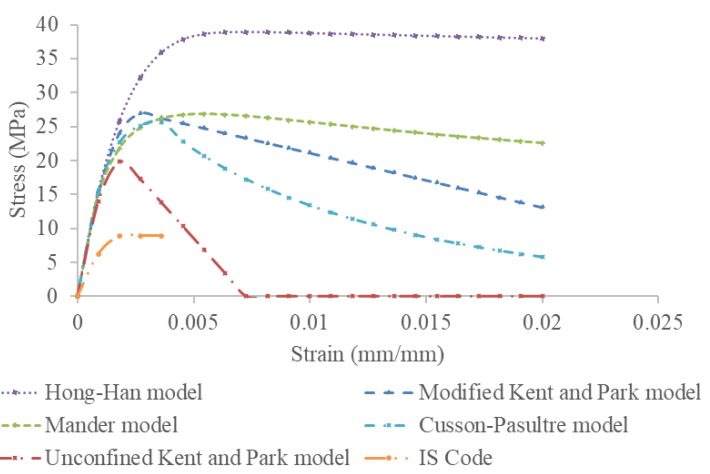

(a) Concrete confined and unconfined material model

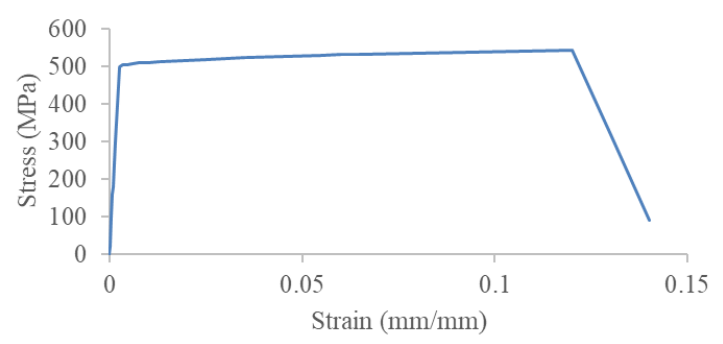

(b) Steel material model

Figure 2: Stress-strain curve of concrete and reinforcement

Kent and Park, (1971) (Kent, D.C., and Park, 1971) provided the stress-strain curve of the unconfined concrete consisting of ascending part (2nd degree parabola) until peak depicting no role of confining steel until this point and equal to cylinder strength, $f_{c}{ }^{\prime}$. Later during 1982, Kent and Park (Park, R., Priestly, M.J.N., and Gill, 1982) further modified the stress strain model of concrete which depicts the enhancement of the strength of concrete with confinement effect

Cusson-Paultre, 1995 (Cusson, D., and Paultre, 1995) and Hong-Hang Model,2005 (Suzuki et al., 2004).proposed stress-strain model for high strength concrete. Cusson-Paultre, 1995 further divided confinement into 3 classes of low, medium and high confinement. Hong-Hang 
Model,2005 was performed his experiment procedure for high strength concrete (40 to $130 \mathrm{MPa})$, yield strength of tie (320 to $1300 \mathrm{MPa})$ and volumetric ratio of tie (0.32 to $1.92 \%)$. Hence, four confined material models were considered comprising of (2-NSC and 2-HSC) for modelling of concrete and in developing the moment curvature relationship of studied column cross-section.

Generally, the stress strain curve of reinforcement steel consists of elastic until $\varepsilon_{y}$, yield plateau (plastic), followed by curvilinear strain hardening until tensile stress reaches its maximum value and finally descending curve in strain softening until necking and fracture (P. Sunitha, 2016).

Table 1: Material Parameters for reinforcement steel bars (Indian Standard, 2000)

\begin{tabular}{|l|l|c|c|c|c|c|c|c|}
\hline Bar. & \multicolumn{1}{|c|}{$D_{b}(\mathrm{~mm})$} & $\begin{array}{c}f_{y} \\
(\mathrm{MPa})\end{array}$ & $\begin{array}{c}f_{u} \\
(\mathrm{MPa})\end{array}$ & $\begin{array}{c}E_{s} \\
(\mathrm{GPa})\end{array}$ & $\begin{array}{c}E_{s h} \\
(\mathrm{MPa})\end{array}$ & $\varepsilon_{s y}$ & $\varepsilon_{u}$ & $\varepsilon_{b}$ \\
\hline $\begin{array}{l}\text { Longitudinal/ } \\
\text { Transverse }\end{array}$ & $\begin{array}{l}4-16,4-12, \\
6 @ 125 \mathrm{mmc} / \mathrm{c}\end{array}$ & 500 & 545 & 200 & 382 & 0.0025 & 0.12 & 0.14 \\
\hline
\end{tabular}

The curve beyond ultimate strain varies linearly and further drops to breaking strain $\left(\varepsilon_{b}\right)$ with stress equal to $90 \mathrm{MPa}$ as per codal provision (Indian Standard, 2000).

\section{Moment curvature Relationship}

Moment curvature relationships are essential during non-linear analysis of the reinforced concrete structures since it represents the sectional behavior under combined axial and bending moments. For any particular crosssection of the member the idealized M-phi diagram consists of three characteristic points. The first point depicts the tensile strength of concrete with start of cracking decreasing the moment of inertia of the cross-section. Second point represents the yielding point of
As depicted in Figure 2 the stress-strain curve of Hong Han model overestimates the actual unconfined compressive strength which might be due to the fact that this material model was developed for high strength concrete. Also, due to confinement effects the compressive strength of all confined models are higher than 20MPa.

The concrete and reinforcement properties for the numerical study was adopted as per the actual testing parameters. Concrete was adopted of strength $20 \mathrm{MPa}$ (2900psi) and stress strain curve as per the various material models and properties of reinforcement was taken as shown in Table 1. the tensile reinforcement. The third point is the point of collapse due to either yielding of tensile reinforcement, compression failure of concrete or very rare but probable mechanism of collapse of both.

For concrete compressive force and its location from extreme compressive fiber, $\gamma k d$ , equivalent rectangular stress block was used having width of mean stress of $\alpha f_{c}{ }^{\prime}$ and depth of $k d$ with considering the total compressive force and location being similar for actual and equivalent stress block. 


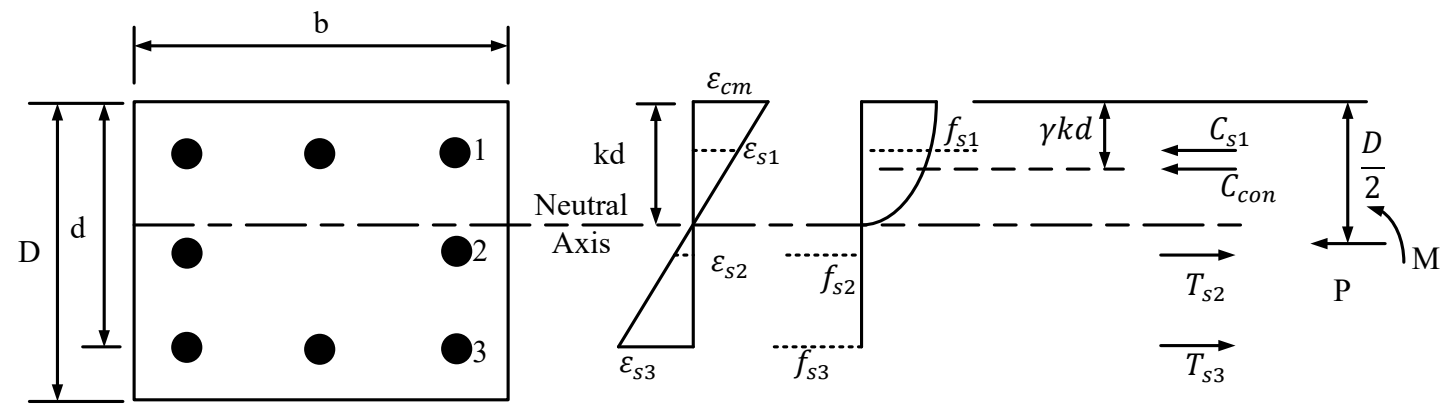

(a) Section (b) Strain Profile (c) Stress (d) Internal forces (e) External actions

Figure 3: Development of Moment curvature relationship

For any strain $\varepsilon_{c m}$ of extreme compression fibre mean stress factor $\alpha$, and centroid factor $\gamma$, was evaluated as:-

Area under stress-strain curve $=\int_{0}^{\varepsilon_{c m}} f_{c} d \varepsilon_{c}=$ $\alpha f_{c}^{\prime} \varepsilon_{c m}$

$\alpha=\frac{\int_{0}^{s_{c m}} f_{c} d \varepsilon_{c}}{f_{c}^{\prime} \varepsilon_{c m}}$

First moment of area was evaluated about origin of area and under stress-strain curve as

$$
\begin{aligned}
& \int_{0}^{\varepsilon_{c m}} f_{c} \varepsilon_{c} d \varepsilon_{c}=(1-\gamma) \varepsilon_{c m} \int_{0}^{\varepsilon_{c m}} f_{c} d \varepsilon_{c}(2) \\
& \gamma=1-\frac{\int_{0}^{\varepsilon_{c m}} \varepsilon_{c} f_{c} d \varepsilon_{c}}{\varepsilon_{c m} \int_{0}^{\varepsilon_{c m}} f_{c} d \varepsilon_{c}}
\end{aligned}
$$

Finally, compressive force in concrete is given by

$$
\begin{aligned}
& P=\alpha f_{c}^{\prime} b k d+\sum_{i=1}^{n} f_{s i} A_{s i} \\
& M=\begin{array}{l}
\alpha f_{c}^{\prime} b k d\left(\frac{D}{2}-\gamma k d\right)+\sum_{i=1}^{n} f_{s i} A_{s i}\left(\frac{D}{2}-\right. \\
\left.d_{i}\right)
\end{array}
\end{aligned}
$$

Curvature, $\varphi=\frac{\varepsilon_{c m}}{k d}$

Using the above theoretical formulations moment capacity and corresponding curvature was evaluated based on variation of strain on the extreme compression fiber. Moment curvature relationship was developed for various confined material models by Microsoft Excel (Visual Basic Application).

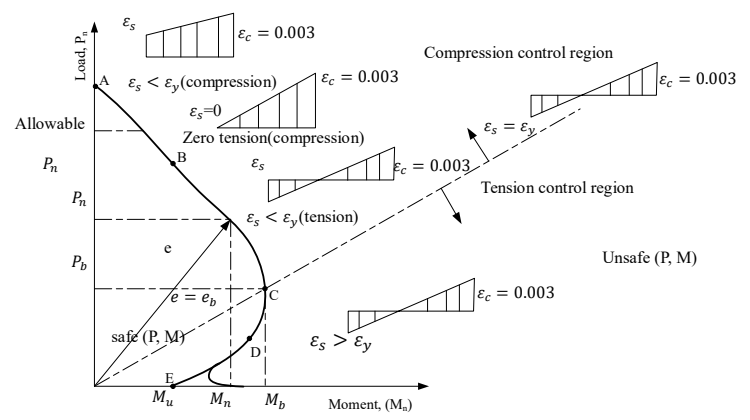

Figure 4: Development of Interaction Curve

\section{Interaction Diagram}

Columns being vertical members are subjected to combined axial load and bending moments due to external loads.

Interaction diagram displays the axial and moment capacity which are acceptable for the studied cross-section of the structural members. Any value of load and moment outside the curve leads to failure of the column which further might be brittle or ductile depending on the location of the point. As depicted in Figure 4 the curve consists of several points with concentric until pure flexure (beam). Hence, in order to consider column as safe (adequate), combination of design strength (M, P) from the curve should be greater than the combination of 
the action effects $(M, P)$.

Using the theoretical formulations of IS (Indian Standard, 2000) and ACI codal (ACI Standard, 2014) provisions interaction curves were developed of studied column section. Interaction curves were generated for various confined material models by Microsoft Excel (Visual Basic Application).

\section{Results and Discussion}

The moment curvature relationship of column for various confined material models with axial load (Axial Load $=0$, pure bending) is depicted in Figure 5.

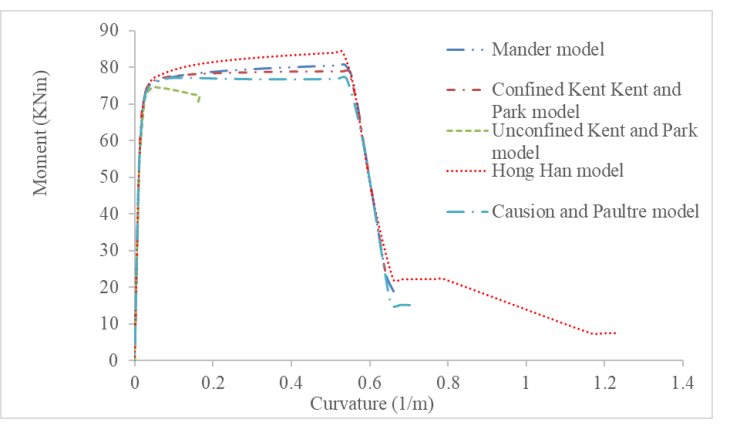

Figure 5: Moment curvature relationship of various material models (Axial load $=0 \mathrm{KN})$

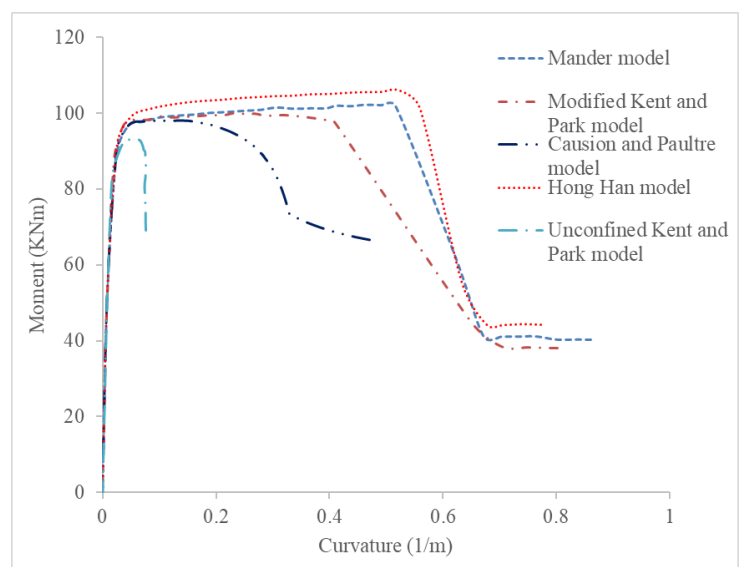

Figure 6: Moment curvature relationship of various material models (Axial load $=200 \mathrm{KN}$ ) The difference in curvature among unconfined and confined material models is shown in
Figure 5. Hence, the presence of transverse reinforcement in confining the core concrete enhances the ductility property of reinforced concrete member with increase in strength. The ultimate curvature of the un confined concrete section considered was obtained approximately to be 0.16 per $\mathrm{m}$ while for studied confined material models the curvature was obtained approximately to be 0.66 per $\mathrm{m}$. Hence, sufficient amount of transverse reinforcement should be provided in structural member to enhance the capacity as well as ductility requirements which is essential for earthquake resistance philosophy. Similarly, for axial compressive load of magnitude $200 \mathrm{KN}$ the moment curvature curve was plotted as shown in Figure 6. From the Figure the ultimate curvature of the unconfined concrete material model was seen to be significantly less as compared to confined concrete model.

The interaction curves as per IS Code and ACI code using finite element application SAP 2000 section designer (Figure 1.) and manual calculation were plotted in Figure 6. It was observed that the plot was almost similar for the studied column section which justifies the mathematical calculation procedure adopted for the study.

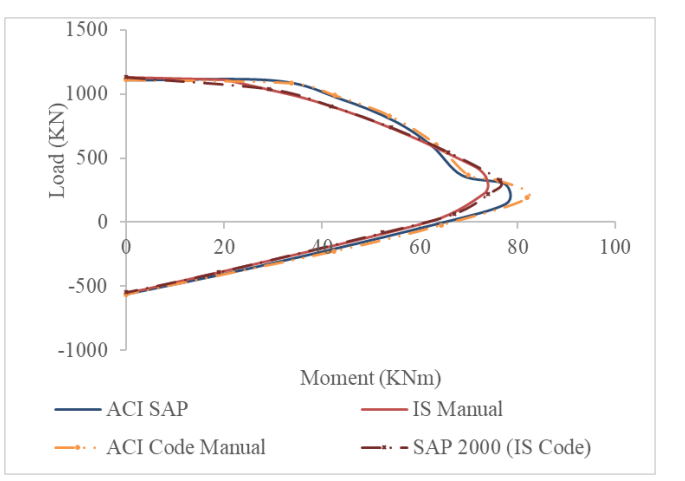

Figure 7: Interaction curve for various codal provisions 


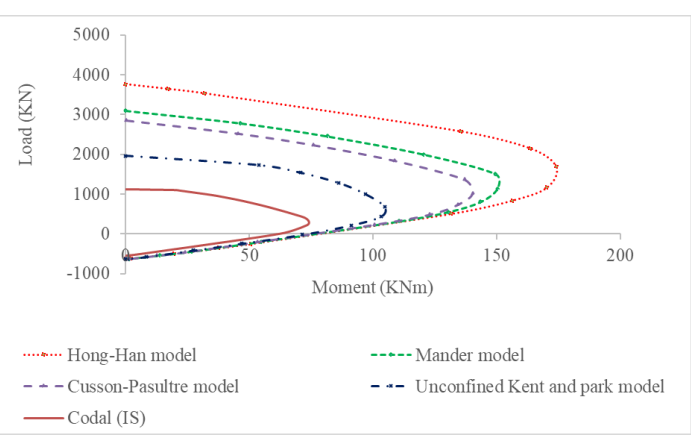

Figure 8: Interaction curve for various material models

For the studied column section, the use of both the codal provision estimated almost similar $\mathrm{P}-\mathrm{M}$ response. Hence, users can adopt any codal provision to design the column section using respective interaction diagram Hence, further study for various material models were performed manually using similar mathematical calculations as shown in Figure 7.

The interaction curves of column for various unconfined confined material model and codal provision (IS) is depicted in Figure 7. It can be clearly observed gain in capacity of axial and bending of the confined concrete in comparison to unconfined one in compression control region.

It is due to the effect of lateral ties which confines the concrete within. Apart from Hong Han model use of other stress-strain concrete material models does not demonstrate significant difference of strength.

\section{Conclusions}

This paper focuses on the evaluation of behavior of a typical column cross-section for moment-curvature and interaction diagrams for various confinement material models and codal provisions. To investigate the effect of material model in obtaining the effect of confinement on stress-strain curve a typical cross-section of column was considered. The results of this study clearly depicts that the major parameter to affect the stress-strain curve of concrete is ultimate strain, maximum stress and corresponding strain. Also, the presence of transverse reinforcement in confining the core concrete enhances the ductility property of reinforced concrete member with increase in strength. The ultimate curvature of the un confined concrete section considered was obtained approximately to be 0.16 per $\mathrm{m}$ while for studied confined material models the curvature was obtained approximately to be 0.66 per $\mathrm{m}$. It was observed that the loss of strength of concrete in cover is compensated by use of the confinement since gain in axial and bending capacity of the confined concrete in comparison to unconfined one in compression control region. Further detailed 3D numerical study is required to be carried to be sure that the confinement results in gain of capacity of $\mathrm{RC}$ structures. Last but not least it is strongly recommended to use the user defined options available in the code of the numerical tool rather than using default properties while adopting the lumped plasticity model in obtaining the response of the structures.

\section{References}

ACI Standard. (2014). Building Code Requirements for Structural Concrete and Commentary on Building Code Requirements for Structural Concrete (ACI 318 R-14). Texas.

Applied Technology Council. (1996). ATC 40 Seismic Evaluation and Retrofit of Concrete Buildings Redwood City California. In Seismic safety commisionsion (Vol. 1).

CP 110. (1972). British code of practice,PART 1. 
Nepal Engineers' Association, Gandaki

Cusson, D., and Paultre, P. (1995). Stress-

Strain Model for confined High-Strength concrete. Journal of Structural Engineering, ASCE, 121(3), 468-477.

Federal Emergency Management Agency. (2000). FEMA-356, Prestandard and commentary for the seismic rehabilitation of buildings. In ASCE (Vol. 36).

Hede, N. P., \& Narayan, K. S. B. (2015). Sensitivity of Pushover Curve to material and geometric modelling-An Analytical investigation. ISTRUC. https://doi. org/10.1016/j.istruc.2015.02.004

Indian Standard. (2000). Plain And Reinforced Concrete Concrete-Code of Practice. In Bureau of Indian Standards, Manak Bhavan, New Delhi 110002. (Vol. 37). https://doi. org/10.14359/8543

J. B. Mander, M. J. N. P. and R. P. (1988). Theoretical stress-strain model for confined concrete. Journal of Structural Engineering, SCE, 114(8), 1804-1826.

Kent, D.C., and Park, R. (1971). Flexural members with confined concrete. Journal of the Structural Division, Proc. of the American Society of Civil Engineers.

Kwak, H., \& Kim, S. (2002). Nonlinear analysis of RC beams based on moment - curvature relation. Computers and Structures, 80, 615628.

P. Sunitha, R. G. and C. V. R. M. (2016). Idealised bilinear moment-curvature curves of RC sections for pushover analysis of RC frame buildings. The Indian Concrete Journal, 90(4), 43-54.
Park, R., and Paulay, T. (1975). Reinforced concrete structures (J. W. and Sons, ed.). New York.

Park, R., Priestly, M.J.N., and Gill, W. . (1982). Ductility of Square Confined Concrete Columns. ASCE Journal of Structural Engineering, 108(11), 929-951.

SAP-2000. (2016). C SI Analysis Reference Manual. Berke ley, Cal i for nia, USA.

Suzuki, M., Akiyama, M., Hong, K., CAMERON, I. D., \& WANG, W. L. (2004). Stress-Strain Model of High-Strength Concrete Confined By Rectangular Ties. 13th World Conference on Earthquake Engineering, (3330).

Thomas, T. (1990). Design Code, CEB-FIP Model Code.

Zendaoui, A., Kadid, A., \& Yahiaoui, D. (2016). Comparison of Different Numerical Models of RC Elements for Predicting the Seismic Performance of Structures. International Journal of Concrete Structures and Materials, 10(4), 461-478. https://doi. org/10.1007/s40069-016-0170-7 